\title{
Association of Fatty Liver and Hypothyroidism
}

\author{
Mohammad Jamshed Alam, Salimur Rahman, Mamun Al-Mahtab
}

\begin{abstract}
Fatty liver is a common problem in the developed and developing countries. Both the patients of fatty liver and hypothyroidism are obese and hyperlipidemic. There may have association between fatty liver and hypothyroidism. This study was done to evaluate the association of fatty liver and hypothyroidism. This cross-sectional prospective study was carried out on 60 patients from J uly 2009 to J une 2011. It was done in the Department of Medicine of Sher-E-Bangla Medical College Hospital, Barisal. There is no association of fatty liver and hypothyroidism.
\end{abstract}

Keywords: Fatty liver, Hypothyroidism, O besity, Hyperlipidemia.

How to cite this article: Alam MJ, Rahman S, Al-Mahtab M. Association of Fatty Liver and Hypothyroidism. Euroasian J Hepato-Gastroenterol 2013;3(1):8-9.

\section{Source of support: Nil}

\section{Conflict of interest: None}

\section{INTRODUCTION}

Fatty liver means accumulation fat largely triglyceride exceeding $5 \%$ of the liver weight. It is caused by failure of normal hepatic fat metabolism either due to a defect within the hepatocyte or to delivery of excess fat, fatty acid or carbohydrate beyond the secretory capacity for lipid of the liver cell. ${ }^{1,2}$ Fatty liver may present as diffuse smooth hepatomegaly in appropriate circumstances such as obesity, diabetes or alcoholism. There is dull ache in right upper abdomen. There is also hypercholesterolemia. Most sensitive investigation of fatty liver is abdominal ultrasonography. Findings include increased echogenicity of liver with or without hepatomegaly. Hypothyroidism is an endocrine as well as autoimmune disorder. It is caused by decrease in thyroid function. The patient of hypothyroidism is obese. There may have diabetes, and hypercholesterolemia. They are present with weight gain, puffy face, hoarse and croaky voice, nonpitting edema in legs, and loss of outer one-third of eye brow, dry skin and bradycardia. ${ }^{3-6}$ There is also delayed relaxation of ankle jerk and hypertension. Laboratory finding of hypothyroidism include low FT3 and FT4 but raised TSH level in blood. Since hypothyroidism is an autoimmune disease, it may be associated with other autoimmune disease like pernicious anemia and diabetes. In this study we try to find out the association of fatty liver and hypothyroidism.

\section{MATERIALS AND METHODS}

The study was carried out on 60 patients with clinically proved fatty liver from J uly 2009 to J une 2011. It was done at the Department of $M$ edicine of Sher-E-B angla M edical College Hospital (SB M CH), B arisal. Patients were selected on the prefixed inclusion and exclusion criteria.

The inclusion criteria included fatty liver of either sex age 18 years or more. The exclusion criteria included patients of cirrhosis of liver, hepatic encephalopathy, hepatocellular carcinoma, hepatorenal syndrome, electrolytes disorders and advanced renal failure (serum creatinine $>2 \mathrm{mg} \%$ ). A fter proper selection 30 patients were admitted into Medicine Department and 30 patients were properly treated at M edicine outpatient department (OPD) of SB M CH, B arisal. A fter admission patients were clinically examined for establishment of diagnosis. The patients who were attended medical OPD were clinically examined for establishment of fatty liver. Ultrasonography of hepatobiliary system of all patients was done. Blood was examined for bilirubin, alanine aminotransferase $(A L T)$, prothrombin time, thyroxin and thyroid stimulating hormone (TSH). A II patients were tested for fasting serum lipid profile and blood sugar.

\section{RESULTS}

The mean age of the patients was $40 \pm 21$ years. B aseline clinical and laboratory data of the patients are shown in Table 1. There were 40 males and the rest two were female. USG of hepatobiliary region was done to assess the echotexture of the liver. The levels of thyroid-related serological markers have been summarized in Table 2 . The levels of fasting cholesterol, fasting triglyceride and fasting blood sugar level were mostly high in these patients.

\section{DISCUSSION}

Fatty liver means accumulation fat largely triglyceride exceeding $5 \%$ of the liver weight. It is caused by failure of normal hepatic fat metabolism either due to a defect within the hepatocyte or to delivery of excess fat, fatty acid or carbohydrate beyond the secretory capacity for lipid of the liver cell. ${ }^{7}$ Fatty liver may present as diffuse smooth hepatomegaly, such as obesity, diabetes or alcoholism. There may be dull ache in right upper abdomen. The prevalence of patients of fatty liver is increasing day by day. Initially these patients do not reveal any specific problem except mild dull ache in upper right abdomen. 


\section{Table 1: Baseline clinical and laboratory data of patients} in the study

- Age (years)

$40 \pm 21$

- Male

40

- Female

20

- S. bilirubin (mg/dl)

- Alanine aminotransferase (IU/I)

- Prothrombin time (seconds)

- Serum creatinine (mg/dl)

- Serum sodium ( $\mathrm{umol} / \mathrm{l}$ )

- Sodium potassium ( $\mu \mathrm{mol} / \mathrm{l})$

- Serum cholesterol (mg/dl)

- Fasting triglyceride (mg/dl)

- USG of HBS

- Increased echogenicity of liver

- Hepatomegaly
$1.0 \pm 0.1$

$50 \pm 10$

$14 \pm 3$

$1.2 \pm 0.2$

$140 \pm 10$

$5.0 \pm 1.0$

$180 \pm 10$

$8.0 \pm 0.5$

60

48

Table 2: Laboratory data for detection of hypothyroidism

$\begin{array}{lc}\text { - } \mathrm{FT}_{3}(\mathrm{nmol} / \mathrm{l}) & 1.5 \pm 0.6 \\ \text { - } \mathrm{FT}_{4}(\mathrm{pmol} / \mathrm{l}) & 15 \pm 6 \\ \text { - } \mathrm{TSH}(\mu / \mathrm{l}) & 2.2 \pm 1.5 \\ \text { - Fasting cholesterol }(\mathrm{mg} / \mathrm{dl}) & 180 \pm 20 \\ \text { - Fasting triglyceride }(\mathrm{mg} / \mathrm{dl}) & 230 \pm 20 \\ \text { - Fasting blood sugar }(\mu \mathrm{mol} / \mathrm{l}) & 7.8 \pm 0.5\end{array}$

Hypothyroidism is an endocrine as well as autoimmune disorder. It is caused by decreased thyroid function. The patient of hypothyroidism is obese. They may have diabetes, and hypercholesterolemia. They may be present with weight gain, puffy face, hoarse and croaky voice, nonpitting edema in legs, loss of outer one-third of eyebrow, dry skin and bradycardia. There is also delayed relaxation of ankle jerk and hypertension. ${ }^{8-11}$

It is likely that there may be an association between fatty liver and hypothyroidism, however, there are few studies about these aspects, especially from developing countries. In this study, we assessed a relationship between these two diverse but associated clinical conditions in 60 patients at our set up. However, we failed to get a clear cut association among different parameters of fatty liver and hypothyroidism. Although the ultimate outcome of the study is a negative one, further study in this context with sample size may provide further insights about this.

\section{REFERENCES}

1. Garcia-M ontoz C, Martin-Parez E, Lacono OL, et al $C$ haracterization of pathogenic and prognostic factor of nonal coholic steatohepatitis associated with obesity. J Hepatol 2000;34:716-24.

2. W anless IR, L entz J S. Fatty liver hepatitis (steatohepatitis) and obesity: A n autopsy study with analysis of risk factor. Hepatology 1990;12:1106.

3. U eno $T$, Sugawara $H$, Sujaku K, et al. Therapeutic effects of restricted diet and exercise in obese patients with fatty liver. J Hepatol 1997;27:103.

4. M atteoni CA, Y ounossi ZM, Gramlich T, et al. Nonalcoholic fatty liver disease: A spectrum of clinical and pathological severity. Gastroenterology 1999;116:1413.

5. M arcgesini G, B rizi M, M orselli L abate A M, et al. A ssociation of nonalcoholic fatty liver disease with insulin resistance. A $m$ J M ed 1999;107:450.

6. A ngulo $P, K$ each J $C, B$ attts $K P$, et al. Independent predictors of liver fibrosis in patients with nonalcoholic steatohepatitis. Hepatology 1999;30:1356.

7. Bacon BR, Faravash MJ, Janny CG, et al. Nonalcoholic steatohepatitis: An expanded clinical entity. Gastroenterology 1994;107:1103.

8. Y onnossi ZM, Gramlich T, Bacon BR, et al. Hepatic iron and nonal coholic fatty liver disease. Hepatology 1999;30:847.

9. J ames 0 , Day C. Nonal coholic steatohepatitis; another disease of affluence. L ancet 1999:353:1634.

10. Strachan M WJ, Walker BR. Endocrine disease. Davidson's principles and practice of Medicine (21st ed) Churchill L ivingstone, Elsevier 2010.

11. Paul A, Fitzgerold MD. Diseases of the thyroid gland. Current medical diagnosis and treatment (48th ed) N ew $Y$ ork: $M$ cG raw Hill 2009.

\section{ABOUT THE AUTHORS}

\section{Mohammad Jamshed Alam (Corresponding Author)}

Department of Hepatology, Sher-e-B angla M edical College, B arisal Bangladesh, e-mail: jemima.jitu@ gmail.com

\section{Salimur Rahman}

Department of Hepatology, Bangabandhu Sheikh M ujib M edical University, Dhaka, B angladesh

\section{Mamun Al-Mahtab}

Department of Hepatology, B angabandhu Sheikh M ujib M edical University, Dhaka, B angladesh 